\title{
Energy budget and methods for determining coordinates for a radiomonitoring system based on a small spacecraft
}

\author{
Altay Aitmagambetov', Yuri Butuzov ${ }^{2}$, Valery Tikhvinskiy ${ }^{3}$, Aigul Kulakayeva ${ }^{4}$, Zhadyra \\ Ongenbayeva ${ }^{5}$ \\ 1,5 International Information Technology University, Almaty, Kazakhstan \\ ${ }^{2}$ Institute of Space Techniques and Technologies, Almaty, Kazakhstan \\ ${ }^{3}$ FSUE Radio Research and Development Institute, Moscow, Russian Federation \\ ${ }^{3}$ Moscow Technical University of Communications and Informatics, Moscow, Russian Federation \\ ${ }^{4}$ Satbayev University, Almaty, Kazakhstan
}

\section{Article Info}

Article history:

Received Jun 14, 2020

Revised Aug 20, 2020

Accepted Sep 7, 2020

\section{Keywords:}

Determination of the coordinates of the RES Low-orbit small spacecraft Radio emission source Radio frequency spectrum Radio monitoring

\begin{abstract}
The existing ground-based radio monitoring systems do not allow performing the functions and tasks of radio spectrum monitoring in a quality manner. Therefore, to improve the efficiency of the radio spectrum monitoring systems for countries with a large territory, such as the Republic of Kazakhstan, it is proposed to use low-orbit small spacecrafts as radio monitoring stations. The analysis of the energy budget of radio lines on the basis of existing radio electronic means on the territory of the Republic of Kazakhstan, carried out in this work, showed the possibility of using loworbit small spacecrafts for performing the functions and tasks of radio monitoring. The paper proposes and develops a method for determining the coordinates of radio emission sources based on the goniometric method using scanning antennas on board of one spacecraft. The ranges of the antenna scanning angles are substantiated, and the estimates of the coordinates determination errors are made. Algorithms have been developed and computer programs have been compiled to determine the coordinates of the radio emission sources, which will make it possible to use this method at the initial stages of developing a radio spectrum monitoring system based on one small spacecraft.
\end{abstract}

This is an open access article under the CC BY-SA license.

\section{Corresponding Author:}

Kulakayeva Aigul

Satbayev University

Satbayev str., 22a, Almaty, Kazakhstan

Email: aigul_k.pochta@mail.ru

\section{INTRODUCTION}

At present, the task of increasing the efficiency of radio monitoring systems does not lose its relevance. The main purpose of radio monitoring systems is periodic or continuous monitoring of the use of the radio frequency spectrum (RFS) [1-2]. In the Republic of Kazakhstan, these functions are carried out by the radio monitoring service only on the basis of ground-based radio monitoring systems [3-4]. Ground-based systems have a number of disadvantages, for example, a limited radio monitoring area, an insufficient number of radio monitoring points throughout the country (the total area of the country is 2,724.9 thousand square $\mathrm{km}$ ), the laboriousness of radiomonitoring procedures in difficult climatic conditions and with rugged topography. It should also be noted that there is insufficient automation of radio monitoring processes. Performing radio monitoring functions with the use of ground-based radio monitoring equipment in large areas with rugged topography complicates the radio monitoring procedure. In this regard, radio monitoring 
based on satellite systems is the most promising for countries with large territories. Such systems have a number of advantages: high efficiency, global visibility, and full coverage of territory.

Methods based on the received signal strength (RSS), the carrier phase of arrival (POA), the time difference of arrival (TDOA), and the angle of arrival (AoA) (or DOA - direction of arrival), frequency difference of arrival (FDOA), Doppler difference (DD), and combined methods consisting of two or more of the above methods are known to determine the location of radio emission sources (RES) [5-7]. To date, TDOA and FDOA methods are most widely used in satellite systems [8-11]. However, such methods require several satellites, which is economically inefficient. Therefore, the implementation of radio monitoring functions based on a single LEO satellite is an urgent problem.

To implement radio monitoring systems based on small spacecraft, it is necessary to conduct a number of studies related to the evaluation and analysis of signals received by an on-board measuring receiver, substantiation of methods for determining the location of ground-based radio emission sources (RES), the choice of structures and orbits of space spacecraft, etc. This paper discusses the issues of assessing the energy budget of the radio lines "Ground RES - On-board measuring receiver", and also algorithms for determining the coordinates of RES for the goniometric method based on the use of one low-orbit small spacecraft (SSC).

\section{RESEARCH METHOD}

\subsection{The energy budget of a radio line and the method for determining RES coordinates}

When creating a radio monitoring system with the use of a small spacecraft, it is necessary to assess the signal levels at the input of the on-board measuring receiver caused by various ground-based radiation emission sources. Such an assessment can be carried out based on the methodology for calculating the energy budget of various radio communication channels in accordance with the recommendations of the International Telecommunication Union [12-17]. An analysis was made in a number of works on calculating the energy budget of radio channels to improve the efficiency of communication systems based on small telecommunication satellites [18-21].

In this work, the parameters of the real ground-based radio electronic equipment operating in the territory of the Republic of Kazakhstan within the frequency range from $94 \mathrm{MHz}$ to $14 \mathrm{GHz}$ are selected for the analysis of the energy budget of the radio line of the radio monitoring system based on SSC. The results of the calculations for a number of ground-based RESs are shown in Table 1.

When solving the problem of determining the location of a RES, it is necessary to choose a method for determining its coordinates. In [22-25], methods for determining the coordinates of radio emission sources using a low-orbit constellation of satellites are considered and proposed. However, it is advisable to consider the use of one SSC at the first stage of creating a radio monitoring system; this will simplify and reduce the cost of the radio monitoring system. To determine the coordinates (latitude and longitude) of the RES based on one SSC, which is in a circular polar orbit (with inclination of $i=90^{\circ}$ ), it is proposed to consider the method, the principle of which is explained in Figure 1.

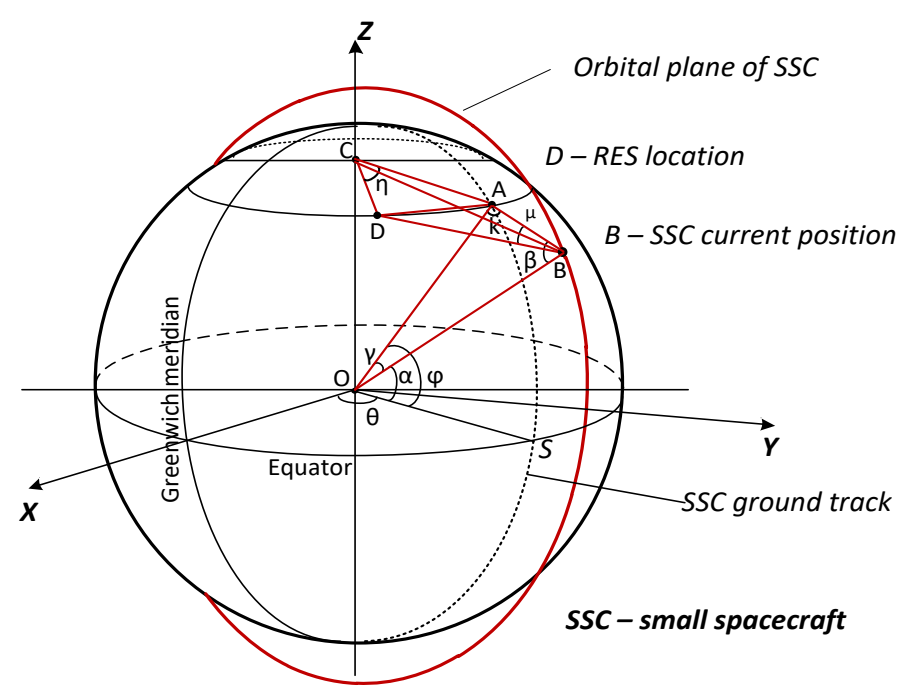

Figure 1. Determination of the RES coordinates on the basis of one SSC 
The figure uses the following designations: O - the centre of Earth mass; D - the RES location; B SSC position. The determination of the RES location latitude was carried out based on the analysis of the parameters of the AOB triangle built in an ellipse (section of the spheroid by the ZOY plane). Point A is located on the surface of the SSC track at the point of its intersection with the parallel on which the RES is located (that is, at the same latitude); side $\mathrm{OA}=\mathrm{Re}$ (Earth radius) depending on latitude $\varphi$; side $\mathrm{OB}=\mathrm{Ro}$ (radius of the orbit of the small spacecraft); $\varphi$ is the RES latitude (the angle between the OA direction and the equatorial plane); $\alpha$ is the latitude of the spacecraft (the angle between the OB direction and the equatorial plane).

Angles in triangle AOB are the following: $(\gamma)$ - latitude difference; the angle is opposite to AB side; $\beta$ is the angle at which point $A$ is visible from the small spacecraft relative to the direction $O B$; it is opposite to the side $\mathrm{OA} ; \mathrm{k}$ is the 3rd angle in triangle, opposite to $\mathrm{OB}$ side. With the known 3 parameters of the triangle, it is easy to find its other parameters. In this case, the OB side and the angle $\beta$ are known (determined during scanning), the remaining parameters depend on the $\varphi$ that needs to be determined. Therefore, we will need to apply the iteration method.

In papers [26-27], a method for determining the RES coordinates using one small spacecraft was considered to determine the RES location. However, the distance OA (Earth's radius) was taken as a constant parameter in this method, which leads to errors in determining the RES coordinates. Since the Earth's surface differs from spherical and has the shape of a geoid, the surface of which is difficult to express mathematically, then when solving a number of practical problems, the surface of a spheroid (ellipsoid of revolution), which is close in shape to a geoid, is taken instead of the surface of the geoid.

The radio monitoring area (RMA) at the territory of the Republic of Kazakhstan is within the range of the northern latitude value from $\varphi=40^{\circ}$ to $\varphi=56^{\circ}$ (average RMA is $\varphi=48^{0}$ ). It is at the middle latitude where we have chosen the orbital altitude of the spacecraft $h$ (in our case, $h=650000 \mathrm{~m}$ ). To determine the radius of the circular orbit Ro, it is required to compute the radius of the ellipsoid (the linear distance from the Earth's centre of mass to the surface), depending on latitude:

$$
R_{e}\left(\phi=48^{0}\right)=\frac{a \times b}{\left[\left(b^{2}+a^{2} \times t g^{2} 48^{0}\right)^{0.5} \times \cos 48^{0}\right]}=6366299[\mathrm{~m}]
$$

where $a=6378136 \mathrm{~m}$ is the equatorial radius of the Earth; $b=6356751 \mathrm{~m}$ is the polar radius of the Earth [28].

Next, we define a number of parameters of the spacecraft orbit:

a) The radius of the circular orbit of the small spacecraft:

$$
R_{o}=R_{e}\left(48^{0}\right)+h=7016299[\mathrm{~m}]
$$

b) Linear velocity of the small spacecraft.

$$
V=\left(\frac{G \times M}{R_{o}}\right)^{0.5}=7542[\mathrm{~m} / \mathrm{s}]
$$

where $\mathrm{M}=5.98 \times 10^{24} \mathrm{~kg}$ is Earth's mass, and $\mathrm{G}=6.6743 \times 10^{-11} \mathrm{~m}^{3} \times \mathrm{kg}^{-1} \times \mathrm{s}^{-2}$ is gravitational constant [29].

c) Time of one SSC revolution.

$$
T=\frac{2 \times \pi \times R_{O}}{V}=5842.264[s]=97.37[\mathrm{~min}]
$$

d) The time when the SSC is over the territory of the Republic of Kazakhstan:

$$
t=\frac{T \times\left(56^{0}-40^{0}\right)}{360^{0}}=4.33[\mathrm{~min}]
$$

Next, it is necessary to calculate the energy budget and analyse the results.

\subsection{Calculation and analysis of the energy budget when operating from ground-based RES}

For the calculation and analysis of the energy budget, the following were chosen as an example of the RES: mobile communication stations of various standards GSM-900 MHz, UMTS-1800 MHz, LTE-2100 $\mathrm{MHz}$; station of terrestrial digital video broadcasting of the standard DVB-T2 (TV) (474 MHz) with 21 television channels; terrestrial sound broadcasting (FM) $94 \mathrm{MHz}$; satellite earth stations operating in the X -7 $\mathrm{GHz}$ and $\mathrm{Ku}-14 \mathrm{GHz}$ bands. The analysis of the signal levels at the radio monitoring system receiver input given in Table 1. showed that for most of the considered ground-based RESs, the SNR ratio is more than 10

\footnotetext{
Energy Budget and Methods for Determining Coordinates for a Radiomonitoring ... (Altay Aitmagambetov)
} 
$\mathrm{dB}$, which is acceptable for radio monitoring. However, it is necessary to use special methods for processing weak signals, on-board receivers with increased sensitivity and high gain antennas (Active Phased Array Antenna, APAA) for the efficient operation of a radio monitoring system based on one small spacecraft.

Table 1. The results of the energy calculation in the upward direction from the ground-based RES of the

\begin{tabular}{|c|c|c|c|c|c|c|c|c|c|c|}
\hline $\begin{array}{c}\text { Radio source } \\
\text { type }\end{array}$ & $\begin{array}{c}\text { Frequency } \\
{[\mathrm{MHz}]}\end{array}$ & $\begin{array}{c}\text { Transmit } \\
\text { power } \\
{[\mathrm{W}]}\end{array}$ & $\begin{array}{c}\text { Antenna } \\
\text { gain } \\
{[\mathrm{dBi}]}\end{array}$ & $\begin{array}{c}\text { Receiver } \\
\text { feed loss } \\
{[\mathrm{dB}]}\end{array}$ & $\begin{array}{c}\text { Effective } \\
\text { Isotropic } \\
\text { Radiated } \\
\text { Power } \\
\text { (EIRP) } \\
\text { [dBW] }\end{array}$ & $\begin{array}{c}\text { Total } \\
\text { Link loss } \\
{[\mathrm{dB}]}\end{array}$ & $\begin{array}{c}\text { Receiving } \\
\text { system } \\
\mathrm{G} / \mathrm{T} \\
{[\mathrm{dBi} / \mathrm{K}]}\end{array}$ & $\begin{array}{c}\text { System } \\
\text { noise } \\
\text { power } \\
{[\mathrm{dBm}]}\end{array}$ & $\begin{array}{c}\text { Receiver } \\
\text { input } \\
\text { power } \\
{[\mathrm{dBm}]}\end{array}$ & $\begin{array}{c}\text { Signal- } \\
\text { to-noise } \\
\text { ratio } \\
\text { (SNR) } \\
{[\mathrm{dB}]}\end{array}$ \\
\hline GSM & 900 & 15 & 1 & 1,2 & 11.56 & 149.8 & -29.5 & -125 & -108.24 & 16.76 \\
\hline UMTS & 1800 & 15 & 1 & 1 & 11.76 & 155.8 & -29.5 & -125 & -114.03 & 10.97 \\
\hline LTE & 2100 & 15 & 1 & 0.9 & 11.86 & 157.6 & -29.5 & -125 & -115.74 & 9.26 \\
\hline TV & 474 & 500 & 1.5 & 1.3 & 17.19 & 144.2 & -29.5 & -125 & -97.01 & 27.99 \\
\hline FM & 94 & 25 & 2 & 1.1 & 14.88 & 130.2 & -29.5 & -125 & -85.32 & 39.68 \\
\hline $\mathrm{X}$ [GHz] & 7 & 25 & 35 & 0 & 48.97 & 169.1 & -29.5 & -125 & -93.13 & 31.87 \\
\hline $\mathrm{Ku}[\mathrm{GHz}]$ & 14 & 27 & 38 & 0 & 52.31 & 175.6 & -29.5 & -125 & -93.29 & 31.71 \\
\hline
\end{tabular}

\section{RESULTS AND DISCUSSION}

\subsection{Analysis of the method for determining the RES coordinates}

To determine the RES coordinates, a structural diagram for the on-board equipment of the space segment of the radio monitoring system based on one low-orbit small spacecraft is proposed (Figure 2). To implement this system, it is necessary to have two antennas of the active phased array (APAA) type on board the small spacecraft. The APAA must have a certain angle of scanning of the earth's surface in order to detect RES. The detected signals from the RES enter the receiver and are further processed according to certain algorithms.

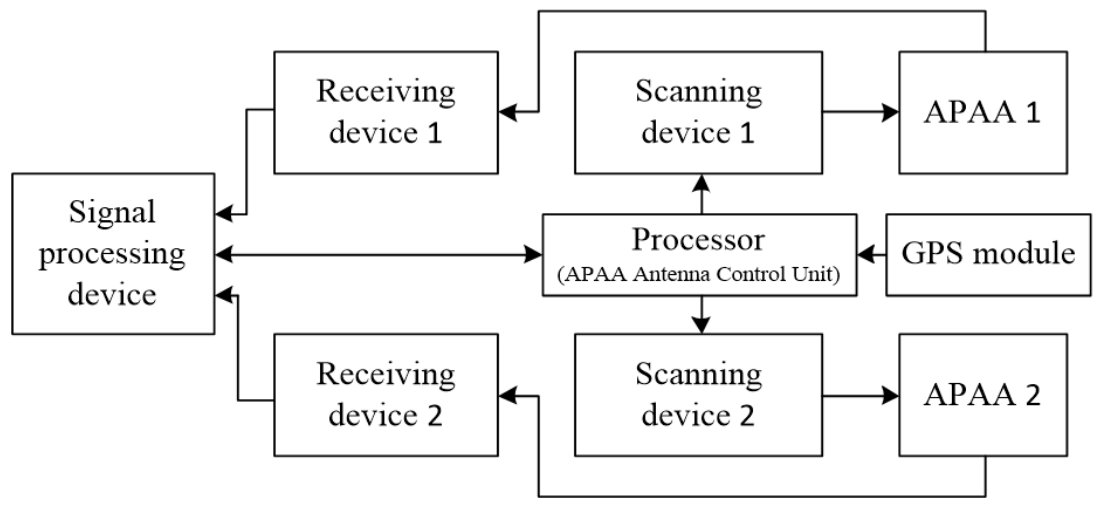

Figure 2. Structural diagram of the space segment of the on-board equipment

\subsection{Proposed algorithm for determining the latitude of the RES location}

Antennas on the small spacecraft should be highly-directional. The beam of one of them scans in the meridian direction (in the direction of movement of the small spacecraft) and serves to determine the latitude of the RES location at the moment of signal recording using the equisignal sector method [30]. The beam of the second antenna scans in the direction orthogonal to the movement of the spacecraft and serves to determine the longitude of the RES location.

As seen from Figure 1, if the $\mathrm{OB}$ side and the angle $\beta$ are known (determined by scanning), the remaining parameters depend on $\varphi$ to be determined. Since only two parameters of the triangle are known, it will be necessary to apply the iteration method. It is also necessary to obtain an answer to the question of what range of RES location point latitudes is "visible" from the orbit of the small spacecraft. To do this, we need to solve the system of equations: 
The canonical equation of ellipse:

$$
\frac{Y^{2}}{a^{2}}+\frac{Z^{2}}{b^{2}}=1
$$

The equation of the tangent to the ellipse from the point where the SSC is located [31]:

$$
\frac{Y_{k} Y_{b}}{a^{2}}+\frac{Z_{k} Z_{b}}{b^{2}}=1
$$

It is convenient to select the SSC coordinates at the equator $\left(Y_{b}=7016299 \mathrm{~m} ; \mathrm{Z}_{b}=0\right)$. First, for $\mathrm{Z}_{b}=0$, we find $Y_{k}=\frac{a^{2}}{Y_{b}}$, and then we find $\mathrm{Z}_{\mathrm{k}}$ :

$$
Z_{k}=\left[\left(1-\frac{a^{2}}{Y_{b}^{2}}\right) \times b^{2}\right]^{0.5}
$$

Coordinates of the point of contact $\mathrm{Z}_{\mathrm{k}}=2648836 \mathrm{~m} ; \mathrm{Y}_{\mathrm{k}}=5798016 \mathrm{~m}$.

The latitude of the point of contact is $\phi_{k}=\operatorname{arctg}\left(\frac{Z_{k}}{Y_{k}}\right)=24.55^{0}$. Thus, the RESs visible from the small spacecraft located at the equator are within the latitude range from $0^{0}$ to $24.55^{\circ}$, that is, outside the territory of Kazakhstan. When the spacecraft move to a latitude of $\alpha=40^{\circ}$, approximately the same range of visible latitudes of the RES locations will remain (from $40^{\circ}$ to $64.55^{\circ}$ ).

It is also important to answer the question of which section of the $\varphi(\beta)$ dependence will reduce the $\varphi$ determining error due to the inaccuracy of the $\beta$ estimate. The answer can be obtained by solving the inverse problem (we determine $\beta$ from known $\varphi$ ). We can perform the calculation using the following formula (the calculation results are shown in Table 2.):

$$
\beta(\phi)=\arcsin \left[R(\phi) \times \frac{\sin (\gamma)}{A B(\gamma)}\right]
$$

Table 2. shows that preference should be given to the initial section of the $\beta(\varphi)$ dependence. Similarly, one can determine the dependences of $\beta$ on $\varphi$ at $\alpha=44^{0}, 48^{\circ}$, and $52^{\circ}$. Let us consider one of the options for solving the direct problem of determining the latitude of the radio source location from the spacecraft. The procedure for determining the latitude of the RES location begins when the spacecraft is at a latitude of $\alpha=40^{\circ}$ (high positioning accuracy can be provided using GPS/GLONASS monitoring). The narrow directed beam of the antenna starts scanning in the meridian direction to the north, starting from the sub-satellite point $\left(\beta=0^{0}\right)$ to $\beta=33.7804^{0}$. This corresponds to a change in $(\gamma)$ from 0 to 4 degrees. At some point, when $\beta=\beta_{1}$, the RES signal is recorded, then disappears. When the beam moves back to the south, the signal at $\beta_{2}$ is recorded again. As a result of using the radio signal zone method, we obtain, for example, $\frac{\left(\beta_{2}-\beta_{1}\right)}{2}=12.0832^{0}$. We compare this value with the average $\beta$ of Table $2 .\left(18.8332^{0}\right)$ and see, it is less. We compare with the next value $\left(9.72798^{\circ}\right.$ ) and finally find that $12.0832^{\circ}$ is greater than $9.728^{\circ}$. This means that the RES location is at the latitude between $41^{\circ}$ and $42^{\circ}$.

Table 2. Dependence of $\beta$ on the latitude of the RES location $\varphi$ at $\alpha=40^{\circ}$.

\begin{tabular}{ccccc}
\hline$\varphi\left[{ }^{0}\right]$ & $\gamma\left[{ }^{0}\right]$ & $\operatorname{Re}(\varphi)[\mathrm{m}]$ & $\mathrm{AB}(\gamma)[\mathrm{m}]$ & $\beta(\gamma)\left[{ }^{0}\right]$ \\
\hline 40 & 0 & 6369274 & 647024.9 & 0 \\
41 & 1 & 6368905 & 657822.6 & 9.72798 \\
42 & 2 & 6368535 & 688504.6 & 18.8332 \\
43 & 3 & 6368163 & 736578.7 & 26.9026 \\
44 & 4 & 6367790 & 798894.6 & 33.7804 \\
\hline
\end{tabular}

We divide this interval in half and calculate $\beta$ at $\varphi=41.5^{\circ}$; it is more again. We divide the lower interval (after the decimal point) in half and calculate $\beta$ at $\varphi=41.25^{\circ}$. We get a value equal to (or close to) the measured value. This means the location of RES is at latitude of $41.25^{\circ}$. If there is no match and a higher accuracy is required, then, depending on the comparison (more or less), we divide the lower or upper intervals after the decimal point in half, calculate $\beta$, and make a comparison, and so on.

Let us consider the possible errors in determining the latitude of the RES according to the above algorithm. The error $\Delta \phi_{o}$ due to the inaccurate setting of the antenna direction to the centre of mass of the Earth (point O) $\Delta \beta_{o}$ (other hardware errors can also be included here) can be determined by the formula: 
$\Delta \phi_{o}=\left(\frac{\Delta \phi}{\Delta \beta}\right) \times \Delta \beta_{o}$

Table 3 shows the average values of the dependence $\frac{\Delta \phi_{o}}{\Delta \beta_{o}}$ with the initial data $\alpha=40^{\circ}$; $\frac{\Delta \phi}{\Delta \beta}=0.1028^{0}($ data from Table 2$)$.

Table 3. Dependency $\frac{\Delta \phi_{o}}{\Delta \beta_{0}}$.

\begin{tabular}{ccccccccccc}
\hline$\Delta \varphi \mathrm{o}\left[{ }^{0}\right]$ & 0.1028 & 0.09252 & 0.08224 & 0.07196 & 0.06168 & 0.0514 & 0.04112 & 0.03084 & 0.02056 & 0.01028 \\
\hline$\Delta \beta \mathrm{o}\left[{ }^{0}\right]$ & 1 & 0.9 & 0.8 & 0.7 & 0.6 & 0.5 & 0.4 & 0.3 & 0.2 & 0.1 \\
\hline
\end{tabular}

This error can be recalculated into linear dimensions using the expression [32] as shown in Table 4:

$$
\Delta l_{o}=\left[R_{e}^{2}\left(40.5^{0}\right)+R_{e}^{2}\left(40.5^{0}+\Delta \phi_{o}\right)-2 \times R_{e}\left(40.5^{0}\right) \times R_{e}\left(40.5+\Delta \phi_{o}\right) \times \cos \Delta \phi_{o}\right]^{0.5}
$$

Table 4. Dependency $\frac{\Delta \phi_{o}}{\Delta \beta_{o}},\left(\Delta \varphi_{\mathrm{o}}\right.$ is expressed in $\left.\mathrm{m}\right)$.

\begin{tabular}{cccccccccccc}
\hline$\Delta \mathrm{lo}[\mathrm{m}]$ & 11427.4 & 102847 & 9141.96 & 7999.22 & 6856.47 & 5713.73 & 4570.98 & 3428.24 & 2255.50 & 1142.75 & 571.374 \\
\hline$\Delta \beta \mathrm{o}\left[{ }^{0}\right]$ & 1 & 0.9 & 0.8 & 0.7 & 0.6 & 0.5 & 0.4 & 0.3 & 0.2 & 0.1 & 0.05 \\
\hline
\end{tabular}

In the second variant of finding the latitude of the $\operatorname{RES}(\varphi), \beta$ and $\alpha$ (latitude of the SSC) are determined simultaneously at the moment of recording the RES signal. The scanning range is smaller, but such that it was possible to use an equisignal sector (depending on the width of the antenna pattern). It can be assumed that the number of iterations to obtain the closest result will be less than in the first option. Iterations start from the value $\varphi=\alpha$.

Let us take the scanning range from the sub-satellite point $\left(\beta=0^{0}\right)$ to $\beta=18.8332^{\circ}$, which corresponds to a change $(\gamma)$ from 0 to 2 degrees. Example: at the moment of signal recording, $\alpha=40.8^{0}$ and $\beta$ $=7.8107^{0}$ are determined.

Iteration 1: we divide the scanning area in $\varphi$ from $40.8^{0}$ to $42.8^{0}$ in half and determine $\beta$ at $\varphi=41.8^{0}$ and $\gamma=$ $1^{0}$. Result $\beta=9.723^{\circ}>7.8107^{0}$.

Iteration 2: we divide the value after the decimal point and choose the lower value $\varphi=41.4^{0}$ while $\gamma=0.6^{0}$ and $\beta=5.877^{\circ}<7.8107^{\circ}$.

Iteration 3: we divide the value after the decimal point and select the upper value $\varphi=41.6^{0}$ while $\gamma=0.8^{0}$ and $\beta=7.8107^{0}$ is equal to the measured value. Answer: $\varphi=41.6^{0}$.

For the example above, $\Delta \varphi / \Delta \beta=0.1024^{0}$, that is, practically did not change relative to $0.1028^{0}$ (at the initial section of the characteristic), therefore, the errors correspond to the values in Tables 3. and 4. At the same time, in the first version, the RES can be located on the final part of the characteristic, where $\Delta \varphi / \Delta \beta=0.1454^{0}$ (the errors will be greater). Conclusion: the second option for solving the problem of determining the RES latitude is better due to smaller errors and a smaller number of iterations. In conclusion, using the last example, we will evaluate the effect of the terrain altitude above sea level on the error in determining the RES location latitude (let $\mathrm{h}=1000 \mathrm{~m}$ ).

Then $\operatorname{Re}\left(41.6^{0}\right)+1000=6369683 \mathrm{~m}$; new value $\mathrm{AB}=653318.427 \mathrm{~m}$, new value $\beta=7.8238^{0}$, change $\Delta \beta=0.013^{0}$, and error $\Delta \varphi=0.1024^{0} \times 0.013^{0}=0.001^{0}$. In linear dimensions, it is approximately equal to $111 \mathrm{~m}$.

The algorithm for determining the RES latitude is shown in Figure 3., and the software application window is shown in Figure 4. 


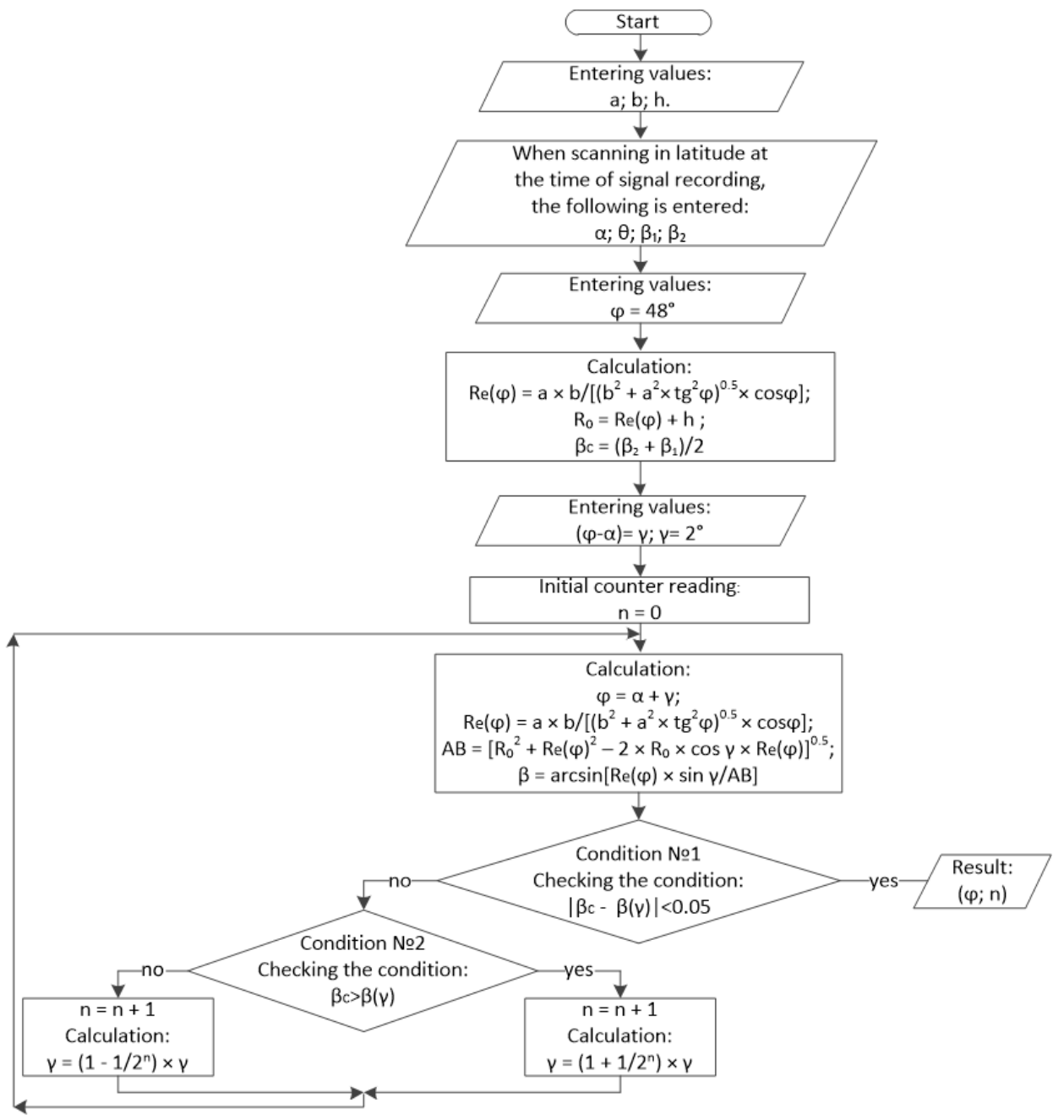

Figure 3. RES latitude determination algorithm

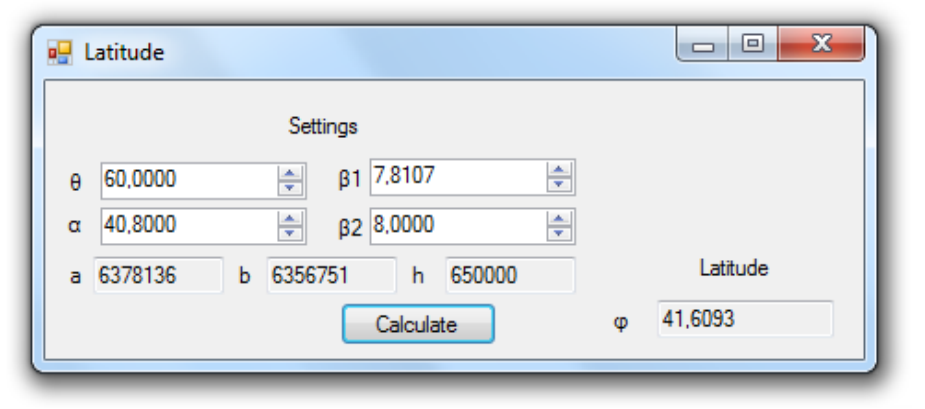

Figure 4. Application window of the program for determining the RES latitude

\subsection{Proposed algorithm for determining the longitude of the RES location}

After determining the RES latitude $\varphi$ (according to the method described in subsection 3.2), we proceed to determining the longitude. Let us consider the features of determining the RES longitude based on the analysis of the parameters of the triangles ABD, ACD, BCD shown in Figure 1. Scanning with the beam relative to point $\mathrm{A}$ is carried out along the parallel corresponding to latitude $\varphi$ in the west and east direction. When a signal appears, the direction to the SRS is registered using the angle $\mu$ ( $\mu$ is the angle between the directions from the SSC (point B) to the RES (point D) and to the point A), as well as the sign of the correction for longitude $\eta$ relative to the SSC position longitude $(\theta)$ - westerly direction $(-)$, easterly 
direction - (+). Figure 1 shows only the western RES location (point D), similarly point D can be at the same angle $\mu$ in the easterly direction.

Point $\mathrm{A}$ is the point of intersection of the above parallel with the ground track of the small spacecraft orbit on the earth's surface. Point $\mathrm{C}$ is located on the $\mathrm{OZ}$ axis at the intersection of its plane along the parallel on which the RES is located (that is, at the same latitude). This section is a circle on which points A and D are located, and point $\mathrm{C}$ is the centre of this circle. Circle radius $\mathrm{R}=\mathrm{AC}=\mathrm{DC}=\operatorname{Re}(\varphi) \times \cos \varphi$.

Side BC is a distance between the SSC and point C, side BD is a distance between the SSC and the RES, side BA is a distance between the SSC and point A; the knowledge of side AD (chord of the circle) is necessary to determine the correction $\eta$. To determine all distances, the coordinates of points A, B, C, and D are required. In the right geocentric coordinate system, we present the formulas for the coordinates of points (the first index is a point; the second is the coordinate origin).

Determine the coordinates of point A:

$$
\begin{aligned}
X_{A O} & =R_{e}(\phi) \times \cos (\phi) \times \cos (\theta) \\
Y_{A O} & =R_{e}(\phi) \times \cos (\phi) \times \sin (\theta) \\
Z_{A O} & =R_{e}(\phi) \times \sin (\phi)
\end{aligned}
$$

Determine the coordinates of the SSC location (point B):

$$
\begin{aligned}
& X_{B O}=R_{O} \times \cos (\alpha) \times \cos (\theta) \\
& Y_{B O}=R_{O} \times \cos (\alpha) \times \sin (\theta) \\
& Z_{B O}=R_{O} \times \sin (\alpha)
\end{aligned}
$$

Determine the coordinates of point $\mathrm{C}$ :

$$
\begin{aligned}
& X_{C O}=0 \\
& Y_{C O}=0 \\
& Z_{C O}=R_{e}(\phi) \times \sin (\phi)
\end{aligned}
$$

When moving the coordinate origin to point $\mathrm{C}(0 ; 0 ; 0)$

Determine the coordinates of point A:

$$
\begin{aligned}
& X_{A C}=R_{e}(\phi) \times \cos (\phi) \times \cos (\theta) \\
& Y_{A C}=R_{e}(\phi) \times \cos (\phi) \times \sin (\theta) \\
& Z_{A C}=0
\end{aligned}
$$

Determine the coordinates of the SSC location (point B):

$$
\begin{aligned}
& X_{B C}=R_{O} \times \cos (\alpha) \times \cos (\theta) \\
& Y_{B C}=R_{O} \times \cos (\alpha) \times \sin (\theta) \\
& Z_{B C}=z_{B O}-z_{A O}
\end{aligned}
$$

Determine the distances

$$
\begin{aligned}
& A C=\left(X_{A C}^{2}+Y_{A C}^{2}\right)^{0.5} \\
& B C=\left(X_{B C}^{2}+Y_{B C}^{2}+Z_{B C}^{2}\right)^{0.5} \\
& B A=\left[\left(X_{B C}-X_{A C}\right)^{2}+\left(Y_{B C}-Y_{A C}\right)^{2}+Z_{B C}^{2}\right]^{0.5}
\end{aligned}
$$

To determine the coordinates of the point $D\left(X_{d}, Y_{d}\right)$, we use the cosine theorem.

$$
\left\{\begin{array}{l}
\left(X_{d}-X_{a}\right)^{2}+\left(Y_{d}-Y_{a}\right)^{2}=\left(X_{b}-X_{a}\right)^{2}+\left(Y_{b}-Y_{a}\right)^{2}+Z_{b}^{2}+\left(X_{d}-X_{b}\right)^{2}+\left(Y_{d}-Y_{b}\right)^{2}+Z_{b}^{2}-2 \times \\
\sqrt{\left(X_{b}-X_{a}\right)^{2}+\left(Y_{b}-Y_{a}\right)^{2}+Z_{b}^{2}} \times \sqrt{\left(X_{d}-X_{b}\right)^{2}+\left(Y_{d}-Y_{b}\right)^{2}+Z_{b}^{2}} \times \cos \mu \\
X_{d}^{2}+Y_{d}^{2}=R^{2}
\end{array}\right.
$$

Further, to determine the coordinates of the point $D\left(X_{d}, Y_{d}\right)$, it is necessary to compose a 4 th degree equation. The resulting equation has the form: 
$X_{d}^{4}\left(A_{2}^{2}+4 A_{4}^{2}\right)+X_{d}^{3}\left(4 A_{2} A_{3}+8 A_{4} A_{5}\right)+X_{d}^{2}\left(4 A_{3}^{2}-2 A_{1} A_{2}-4 R^{2} A_{4}^{2}+4 A_{5}^{2}\right)+X_{d}\left(-4 A_{1} A_{3}-\right.$ $\left.8 R^{2} A_{4} A_{5}\right)+A_{1}^{2}-4 R^{2} A_{5}^{2}=0$

where $A_{1}-A_{5}$ are coefficients depending on the source data.

To solve this equation, a $\mathrm{C} \#$ program was developed.

After determining the coordinates of the point $D\left(X_{d}, Y_{d}\right)$, it is necessary to determine the segment AD:

$A D=\left[\left(X_{d}-X_{a}\right)^{2}+\left(Y_{d}-Y_{a}\right)^{2}\right]^{0.5}$

Using $A D$ and $R$, we determine the correction for longitude $(\eta)$ :

$\eta=2 \times \arcsin \left(\frac{A D}{2 R}\right)$

Determine the longitude of the RES (v):

Longitude of the RES $v=\theta-\eta$ (if the RES is west of the SSC)

Longitude of the RES $v=\theta+\eta$ (if the RES is east of the SSC)

The block diagram of the developed algorithm is shown in Figure 5., and the software application window is shown in Figure 6.

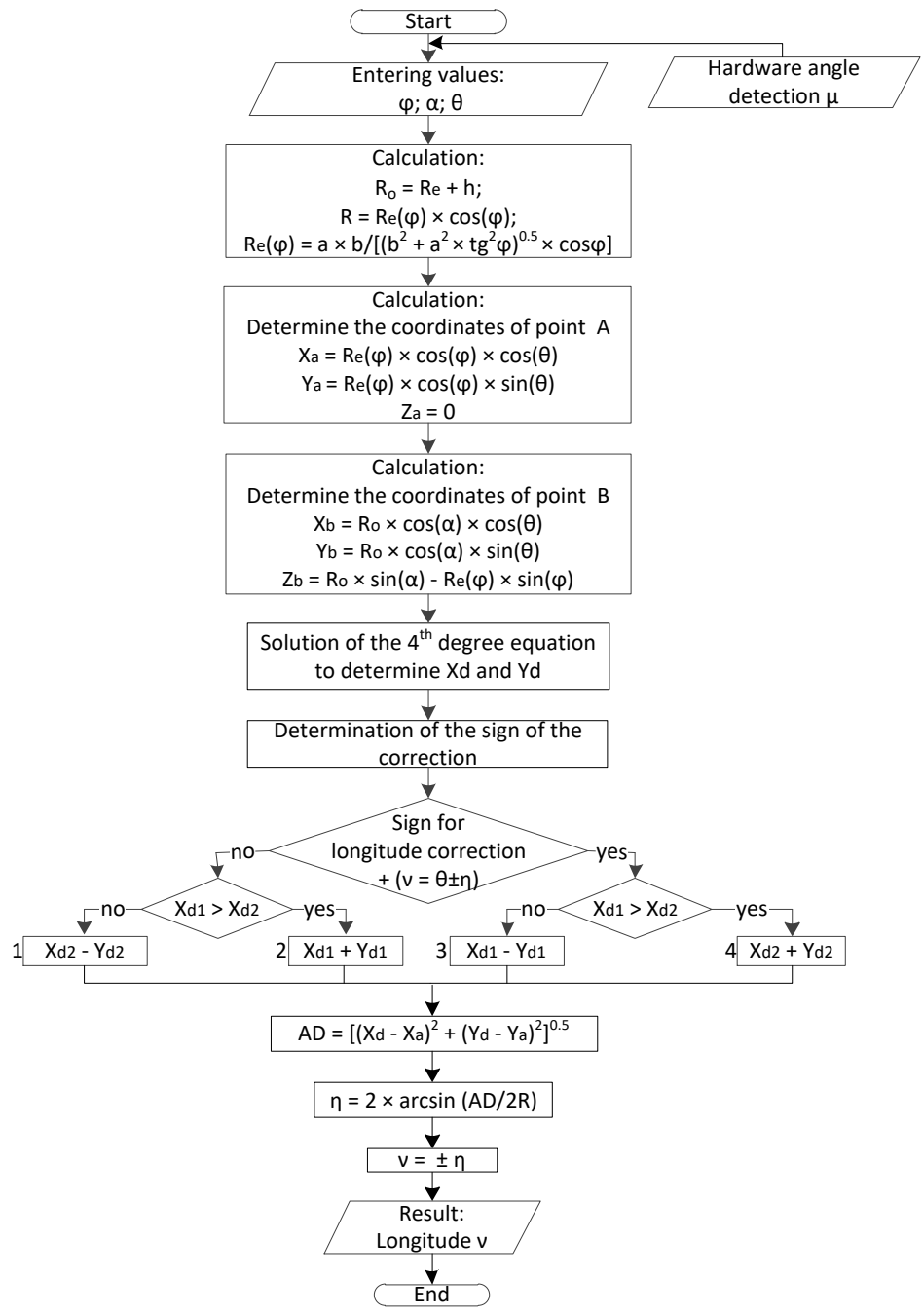

Figure 5. Algorithm for determining the RES longitude 

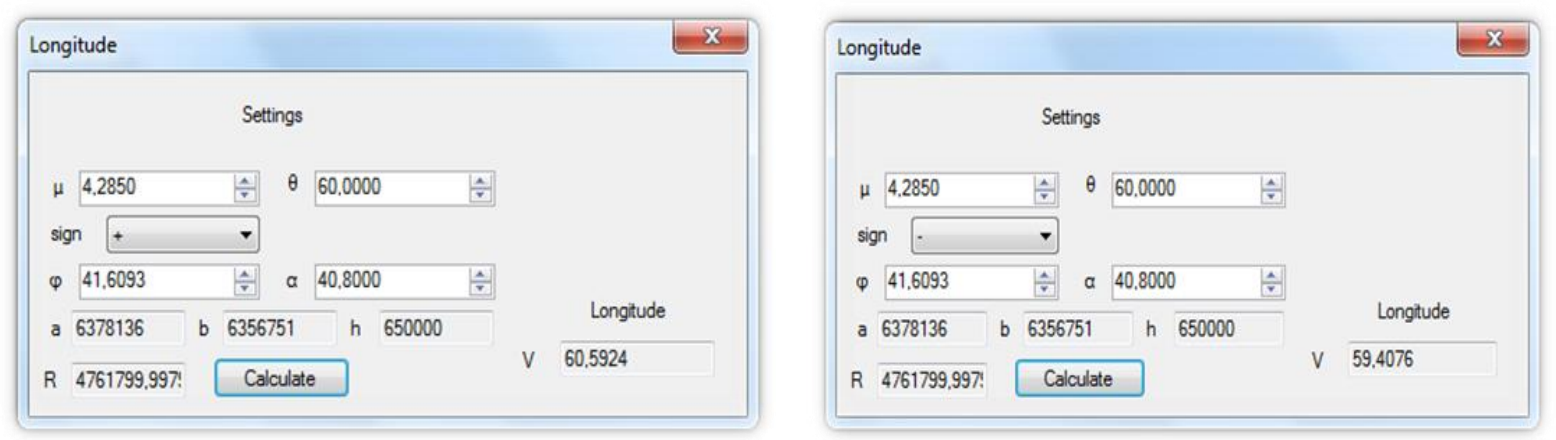

Figure 6. Application window of the program for determining the RES longitude

The developed algorithms and programs for determining the latitude and longitude of the RES are proposed for use in satellite radio monitoring systems based on one small spacecraft.

\section{CONCLUSION}

To increase the efficiency of the radio monitoring system in large areas, it is advisable to use loworbit satellites as radio monitoring stations. In this work, to analyze the budget of the radio link "EarthSatellite", we considered terrestrial sources of radio emission, such as mobile communication stations, terrestrial digital television and sound broadcasting, and earth satellite communication stations. The analysis showed the possibility of using a low-orbit small spacecraft for radio spectrum monitoring systems. The paper proposes and develops the method for determining the coordinates of radio emission sources based on the goniometric method using scanning antennas on board of one spacecraft. When calculating the latitude of the location of radio emission sources, the iteration method was used, and when calculating the longitude, a solution of the fourth degree equation was used. The ranges of the antenna scanning angles are substantiated, and the estimates of the coordinates determination errors are made. Algorithms have been developed and computer programs have been compiled to determine the coordinates of radio emission sources, which will allow to use the proposed method at the initial stages of developing a radio spectrum monitoring system based on one small spacecraft. Further research should be directed to the development of effective antenna systems (Active Phased Array Antenna - APAA) and methods to improve the reliability of detection and recognition of radio signals from radio sources to improve the quality of radio monitoring.

\section{REFERENCES}

[1] Handbook on Spectrum Monitoring. Radiocommunication Bureau, 2011. Geneva, Electronic Publication

[2] Rembovsky, A.M., Ashikhmin, A.V., Kozmin V.A., Smolskiy S.M. Radio Monitoring: Automated Systems and Their Components. Springer International Publishing, p. 486, 2018. ISBN: 978-3-319-74276-2

[3] Official site of the RSE "State Radio Frequency Service", Ministry of Digital Development, Innovation and Aerospace Industry of the Republic of Kazakhstan. https://rfs.gov.kz (date of treatment 03/20/2020)

[4] Law of the Republic of Kazakhstan dated July 5, 2004 N 567 "On Communications"

[5] Dempster, A. G., Cetin, E. Interference Localization for Satellite Navigation Systems. Proceedings of the IEEE, vol. 104, no. 6, p. 1318-1326, 2016. DOI: 10.1109/JPROC.2016.2530814

[6] Report ITU-R SM.2211-2. Comparison of time-difference-of-arrival and angle-of-arrival methods of signal geolocation. SM Series, Spectrum management, 2018.

[7] Zhao, L., Yao, G., Mark, J.W. Mobile positioning based on relaying capability of mobile stations in hybrid wireless networks. IEE Proceedings - Communications, vol. 153, no. 5, p. 762-770, 2006. DOI: 10.1049/ip-com:20050142

[8] Ho, K. C., Chan, Y. T. Geolocation of a Known Altitude Object From TDOA and FDOA Measurements. IEEE Transactions on Aerospace and Electronic Systems, vol. 33, p. 770-783, 1997. DOI: 10.1109/7.599239

[9] Amishimaa T., Suzuki. N. TDOA/FDOA geolocation in space radio monitoring using RLMS and gating. IEICE Communications Express, vol. 8, no. 6, p. 207-212, 2019. DOI: 10.1587/comex.2018XBL0140

[10] Yan, H., Cao, J. K., Chen, L. Study on location accuracy of dual-satellite, ICSP2010 Proceedings, pp. 107-110, 2010. DOI: 10.1109/ICOSP.2010.5656806

[11] Cao Yalu, Peng LI, Li Jinzhou, Yang Le, Guo Fucheng. A new iterative algorithm for geolocating a known altitude target using TDOA and FDOA measurements in the presence of satellite location uncertainty, Chinese Journal of Aeronautics, vol. 28, no. 5, p. 1510-1518, 2015. DOI: 10.1016/j.cja.2015.08.015

[12] ITU-R Recommendations P.618-13. Propagation data and prediction methods required for the design of Earthspace telecommunication systems. Geneva, Electronic Publication, p. 27, 2017. 
[13] ITU-R Recommendations P.840-7. Attenuation due to clouds and fog. Geneva, Electronic Publication, p. 4, 2017.

[14] ITU-R Recommendations P.838-3. Specific attenuation model for rain for use in prediction methods. Geneva, Electronic Publication, p. 8, 2005.

[15] ITU-R Recommendations P.676-11. Attenuation by atmospheric gases. Geneva, Electronic Publication, p. 23, 2016.

[16] ITU-R Recommendations P.835-6. Reference Standard Atmospheres. Geneva, Electronic Publication, p. 10, 2017.

[17] ITU-R Recommendations P.453-13. The radio refractive index: its formula and refractivity data. Geneva, Electronic Publication, p. 23, 2017.

[18] Roger L. Freeman. Radio System Design for Telecommunications $-3^{\text {rd }}$ ed. IEEE, Wiley-Inerscience publication. $\mathrm{p}$. 911. 2006. ISBN: 978-0-471-75713-9

[19] Arum, A., Sreeja, T.K. An Effective Downlink Budget for 2.24 GHz S-Band LEO Satellites. Proceedings of 2013 IEEE Conference on Information and Communication Technologies (ICT 2013), p. 342-344, 2013. DOI: 10.1109/CICT.2013.6558117

[20] Popescu, O. Power Budgets for CubeSat Radios to Support Ground Communications and Inter-Satellite Links. IEEE Access, vol. 5, p. 12618-12625, 2017. DOI: 10.1109/ACCESS.2017.2721948.

[21] Bruce R. Elbert. The Satellite Communication Applications Handbook $-2^{d}$ ed. Artech House, Inc. Boston London, p. 552, 2004. ISBN: 9781580534901

[22] Aitmagambetov, A.Z., Butuzov, Yu.A., Kulakayeva, A.E. Mathematical models for determining the location of radio emission sources in radio monitoring systems on the basis on low-orbit satellites. T-Comm, vol. 10. No.I. p. 73-76, 2016.

[23] Levanon, N. Quick position determination using 1 or 2 LEO satellites. IEEE Transactions on Aerospace and Electronic Systems, vol.34, no.3, p.736-754, Jul 1998.DOI 10.1109/7.705883

[24] Pattison, T., Chou. S. Sensitivity analysis of dual-satellite geolocation. IEEE Transactions on Aerospace and Electronic Systems, vol. 36, no. 1, p. 56-71, 2020. DOI: 10.1109/7.826312

[25] Mason, J. Algebraic two-satellite TOA/FOA position solution on an ellipsoidal Earth, IEEE Trans. Aerosp. Electron. Syst., vol. 40, no. 3, pp. 1087-1092, 2004. DOI: 10.1109/TAES.2004.1337476

[26] Aitmagambetov, A.Z., Butuzov, Yu.A., Kulakayeva, A.E. Method of determining coordinates of radiation source with a single spacecraft. Certificate about deposition of object of intellectual property. 2016, Registration № 002688

[27] Aitmagambetov, A.Z., Butuzov, Yu.A., Kulakayeva, A.E. The principle of determination of coordinates (width and longitude) radio-frequency radiation source. Certificate about deposition of object of intellectual property, 2016. Registration № 2784

[28] Earth parameters 1990 (PZ-90.11). Reference document. Military Topographic Directorate at the General Staff of the Armed Forces of the Russian Federation, p. 52, 2014. (in Russian)

[29] CODATA Recommended values of the fundamental physical constants, 2019.: 2018 NIST SP 961.

[30] Skolnik, M.I. Radar Handbook, Third Edition. McGraw-Hill Education, 2008, p.1325 ISBN: 9780071485470

[31] Ostermann, A., Wanner, G. Geometry by its history. Springer-Verlag Berlin Heidelberg, 2012, ISBN 978-3-64229162-3

[32] Yuzhaninov, V.S. Cartography with the basics of topography. Moscow. "High School" pp. 301, 2001.

\section{BIOGRAPHIES OF AUTHORS}

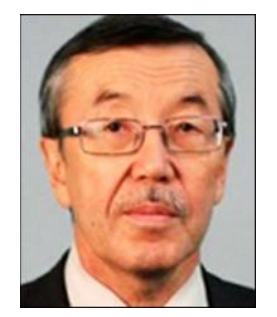

Altay Aitmagambetov Professor of Radio Electronics and Telecommunications Department of International IT University, Candidate of Technical Sciences, Academician of the International Academy of Communications. The author of more than 150 educational and scientific works. Professional experience and scientific interests are: Radio technologies of telecommunications, Control and effective usage of radio spectrum.

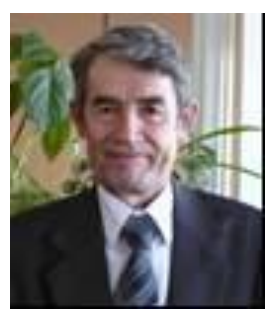

Yuri Butuzov Senior Researcher, Institute of Space Engineering and Technology, Ph.D., Associate Professor. He worked in research institutes and experimental design bureaus for the development of radio communications. The author of more than 80 scientific and methodological works, of which 19 are copyright certificates, 3 patents. He took part in the creation of regulatory technical documents on communications, including the Space Program of the Republic of Kazakhstan. 


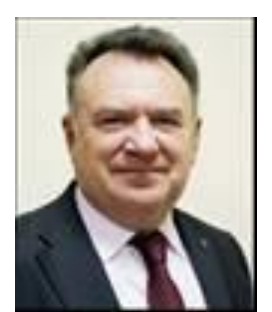

Valery Tikhvinskiy is a Deputy General Director of National Research Institute of Technologies and Communications and Chief Researcher of Radio Research \& Development Institute. He is the Chairman of the Information and Telecommunications Technologies branch of the Russian Academy of Natural Sciences (ITT RAEN). He received a Ph.D. in Radio Engineering (1988). He is Chief Editor of "T-Comm: Telecommunications and Transport" Journal (since 2007) an Editorial Board Member of Electrosvyaz and the Mobile Telecommunications Journals.

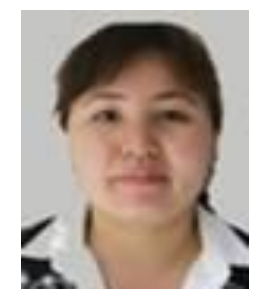

Aigul Kulakayeva she is currently a PhD student of Electronics, telecommunications and space technologies Department at Satbayev University, Kazakhstan. Professional experience and scientific interests are in following fields: Radio technologies of telecommunications; Spectrum monitoring.

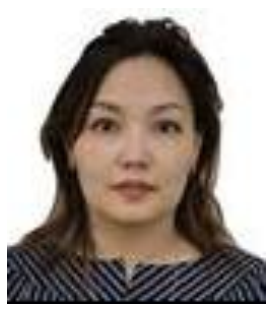

Zhadyra Ongenbayeva she received a master of science degree in computer engineering and software in 2017. Her research interests include programming and modeling of computer networks. 